\title{
Rewarding Multitasking: Negative Effects of an Incentive on Problem Solving Under Divided Attention
}

\author{
Mareike B. Wieth ${ }^{1}$ and Bruce D. Burns ${ }^{2}$
}

\author{
Corresponding Author: \\ Mareike B. Wieth, Department \\ of Psychological Science, Albion \\ College, 611 E. Porter St., Albion, \\ MI 49068. \\ Email: mwieth@albion.edu
}

${ }^{1}$ Albion College, ${ }^{2}$ University of Sydney

\section{Keywords:}

Multitasking, incentives, problem solving

\begin{abstract}
Research has consistently shown negative effects of multitasking on tasks such as problem solving. This study was designed to investigate the impact of an incentive when solving problems in a multitasking situation. Incentives have generally been shown to increase problem solving (e.g., Wieth \& Burns, 2006), however, it is unclear whether an incentive can increase problem solving while attentional resources are divided. Participants were either given an incentive or not and asked to complete incremental and insight problems while either in a dual-task or single task condition. After solving the problems participants were given a surprise memory test. Results showed that the incentive only led to increases in problem solving in the single task condition but not the dual-task condition. Furthermore, results showed that an incentive in the dual-task condition led to an increase in recall of irrelevant information. These findings indicate that an incentive cannot ameliorate the detrimental effects of multitasking when problem solving and may even lead to an increase in irrelevant information processing.
\end{abstract}

The ability to problem solve is often seen as an essential skill for individuals to succeed in today's world. The new Common Core State Standards Initiative, an educational initiative for grades K-12 in the United States, was designed to enhance students' problem solving and critical thinking skills, which are mentioned as crucial for entry-level careers, first-year college courses, and workforce training programs (Common Core State Standards Initiative, 2014). Indeed, problem solving ability has been reported as one of the top two job skills that employers are looking for when hiring (Casserly, 2012). Given the emphasis that has been placed on problem solving in educational and career settings, it is surprising that rather than focusing solely on solving a problem, many students and workers will engage in problem solving activities while also performing other tasks such as checking e-mail or watching TV. Indeed, simultaneously attending to multiple streams of information while working or studying has become an increasingly common behavior among younger individuals, such as college students (Rosen, Carrier, \& Cheever, 2013). Rideout, Foehr, and Roberts (2010), in a report written by for the Kaiser Family Foundation, found that almost a third of the students surveyed said that when they were writing a paper or completing a problem, "most of the time" they were also watching $\mathrm{TV}$, texting, listening to music, or using some other medium. Similarly, a national survey of 2,000 U.S. information workers showed that 92 percent of respondents confessed to multitasking during meetings and 41 percent admit to doing so "often" or "all the time" (FuzeBox, 2014).

Incidence of multitasking continues to increase despite research consistently showing adverse impacts on task performance when switching between two cognitively demanding tasks or attempting to divide attentional resources to perform two tasks at once. For example, Bowman, Levine, Waite, and Dendron (2010) found that students, who were chatting via instant messenger while reading a passage from a textbook took significantly more time to read the passage than students who were engaging in the reading task alone. Similarly, reading comprehension and memory have been shown to be significantly reduced in students completing academic work while watching television (Armstrong, Boiarsky, \& Mares, 1991; Pool, Koolstra, \& van der Voort, 2003). Likewise, costs associated with switching between two tasks have been established in the literature (e.g., Rogers \& Monsell, 1995; Meuter \& Allport, 1999; Rubinstein, Meyer, \& Evans, 2001; Yeung \& Monsell, 2003). For example, Rubinstein, Evans, and Meyer (2001) asked participants to switch between different tasks such as classifying geometric objects and solving math problems. For all tasks, the participants lost time when they had to switch from one task to another. As tasks got more complex, switch cost increased. Moreover, Rogers and Monsell (1995) found that even when participants were asked to make a completely predictable switch between two tasks every two or four trials, they were still slower on taskswitch than on task-repeat trials. Additionally, increasing the time available between trials for preparation reduced but did not eliminate the cost of switching. These findings indicate that switch costs do not simply occur because of time constraints but are also linked to limits in attentional resources.

When looking at the effect of added cognitive load on problem solving in particular, similar negative impacts on 
performance have been seen. For example, Logie, Gilhooly, and Wynn (1994) found that performance on a mental addition task was significantly reduced when participants were asked to also perform a variety of secondary tasks (e.g., concurrent random letter generation, articulatory suppression). Similar results were found by Gilhooly, Logie, Wetherick, and Wynn (1993) for a syllogistic reasoning task. Investigating everyday problem solving, Goddard, Dritschel, and Burton (1998) found reduced performance on the Means-End Problem Solving (MEPS) task when participants were asked to perform a letter response task while listing solutions to daily social problems. Investigating the impact of a secondary task on different types of problem solving processes, Lin and Lien (2013) had participants perform a version of the Wason's 2-46 task as well as a Torrence Test of Creative Thinking (TTCT) while reading aloud a series of consecutive integers. Results showed significantly lower accuracy on the 2-4-6 task for participants in the dual-task condition compared to participants in the single-task condition. The reverse effect was found for the Creative thinking test (TTCT). Participants in the dualtask condition showed greater performance on many of the measures of the Creative thinking test (especially those related to the number of generated responses) compared to participants in the single task condition. Likewise, Lavric, Forstmeier, and Rippon (2000) found evidence for decrements in task performance for an incremental problem but not for an insight problem. Lavric et al. had participants solve the Wason card selection task (incremental problem) and Duncker's candle problem (insight problem) while concurrently counting auditory stimuli. Decrements were seen for the Wason card selection task but not for Duncker's candle problem, indicating that there may be an advantage to reduced attentional processing for tasks involving creativity as seen in Wieth and Zacks (2011) and Jarosz, Colflesh, and Wiley (2012) (see Van Stockum \& DeCaro, 2014 for research showing detrimental effects of increased attentional processing when solving insight problems). Overall though, research consistently indicates that multitasking situations pose an attention allocation problem where limited resources have to be distributed across various tasks to meet some criterion of performance. When the task demands outweigh the available attentional resources, generally decrements in performance are seen. In particular, Wickens $(1980,1984)$ proposed a three-dimensional space of task characteristics (stages of processing, codes, and modalities) that determines interference between tasks. Greater overlap in attentional requirements between two tasks leads to performance decrements in both tasks if participants are performing the tasks simultaneously. If more attention is allocated to one over the other task then greater decrements will be seen in one task.

Kahneman (1973) argued that an individual's enduring dispositions, momentary intentions, and evaluation of the capacity demands will influence the allocation of attentional resources. Those tasks that are seen as more appealing, interesting, or important receive more attention than tasks seen as unappealing, boring, and unimportant. One way of changing the appeal of a task is to associate an incentive with the completion of the task. For example, when looking at worker productivity LaMere, Dickinson, Henry, Henry, and Poling (1996) found that truck drivers increased their productivity after an incentive pay system was introduced which rewarded the drivers for accomplishing each job they had to perform (e.g., delivering goods, loading and unloading goods) compared to a base rate system of pay (a set hourly wage). This increase in productivity was sustained over a period of nearly four years and was not accompanied by worker dissatisfaction or increases in accidents. Similarly, Saari and Latham (1982) studied the performance of beaver trappers before the implementation of an incentive plan and under the incentive plan. It was found that the number of rodents trapped per hour increased significantly under the incentive plan (payment for each beaver trapped) compared to the base rate system of pay (a set hourly wage), which was in place before the incentive plan. Investigating the impact of an incentive on problem solving, Glucksberg (1962) found that incentives increased problem solving performance on an easy version of Duncker's candle problem (the tacks had already been removed from the tack box) but decreased problem solving on the regular version of the problem (for a similar detrimental incentive effect on the Luchins Water Jar task see McGraw \& McCullers, 1979). Wieth and Burns (2006), however, found that incentives led to increases in incremental and insight problem solving. More specifically, participants that were given an incentive (the opportunity to leave the experiment early) had greater problem solving rates than those not given the incentive. Additionally, Wieth and Burns found that participants in the incentive condition had greater memory for the problems than participants not given an incentive. These findings indicate that an incentive may indeed influence performance by altering attention allocation, as proposed by Kahneman (1973). (Similar changes in attention allocation while solving an object assignment problem have been seen when using a penalty points system [Taatgen, 2011]).

\section{CURRENT STUDY}

The primary goal of the current study is to investigate how an incentive influences problem solving while engaging in a multitasking situation. Charon and Koechlin (2010) showed that incentives can alter participants' attention allocation on concurrently performed letter judgment tasks. More specifically, Charron and Koechlin had participants perform letter sequencing tasks where participants had to judge whether two successively presented letters are also in immediate 
succession in the word "tablet" on each trial. Each task (primary and secondary) was assigned either a small incentive $(€ 0.04)$ or a large inventive $(€ 1.0)$, with the assigned value changing throughout the experiment. Charron and Koechlin found that participants' performance changed based on the amount of the incentive such that performance improved as the incentive increased. Given that attention allocation could be controlled with an incentive, we used a dual task, or multitasking approach, to study how incentives affect problem solving when performing two tasks at once. Based on Charron and Koechlin's (2010) finding that incentives can change performance on a primary task even when a second task is present, it is hypothesized that an incentive will cause participants to shift their attentional resources to the rewarded task (problem solving in this case) and away from the nonrewarded task. If this is the case then participants given an incentive in the dual-task condition should show greater problem solving performance but have lower secondary task performance than participants not given an incentive. On the other hand, problem solving entails more attention than the letter sequencing task used by Charron and Koechlin (2010). Indeed, problem solving is an activity that requires a great deal of attentional resources (Hambrick \& Engle, 2003). Perhaps by adding a secondary task that the brain cannot easily ignore (a tone monitoring task), the brain's attentional resources are at their maximum capacity and therefore cannot be easily manipulated. Thus, an incentive may not be able to have an impact on problem solving in a multitasking setting because of the limited additional resources available. If this is the case then an incentive will have no effect on participants engaging in the secondary task while problem solving; the usual detriments of multitasking should be seen.

A secondary goal of this study is to investigate how an incentive may impact memory for problems in a multitasking situation. As discussed above, studies have consistently shown a decrease in memory when engaging in more than one task at a time (e.g., Armstrong, Boiarsky, \& Mares, 1991; Pool, Koolstra, \& van der Voort, 2003). These findings are consistent with Logan and Etherton (1994) who provided evidence that attention is crucial for memory. More specifically, some participants were told to pay attention to both words in a word pair to make a series of judgments while others were told to focus on the colored word in the pair. Results showed that participants that focused on both words showed a performance advantage from the consistent pairing but participants that focused on the colored word did not. Perhaps this is also how an incentive influences problem solving when multitasking. The incentive might serve the same function as the color cue and direct participants' attention to the information that is perceived as relevant in the rewarded task, especially when attentional resources are limited due to performing more than one task at a time. It is therefore hypothesized that participants in the dual-task condition given an incentive will remember more problem relevant information than irrelevant information It is also possible, however, that problem solving is so attentionally demanding that only surface level processing will occur when presented in a dual-task context, regardless of presented incentive. Foerde, Knowlton, and Poldrack (2006) found that a dual-task condition (tone counting) led to an increase in habitual learning and a decrease in declarative learning during a weather prediction task. Participants' accuracy on the weather prediction task in the dual-task trials did not decrease compared to the single task trials, however, results for the cue prediction task immediately following the weather prediction task showed less flexible and more habitual learning for those cues learned during the dual-task trials compared to the single task trials. It is possible that an incentive in the dual-task condition will increase attention to surface level features without increasing attention to relevant meaning in the problem, since the problem solving is so taxing. Increased attention to the surface level, but not relevant meaning, would lead to more habitual learning or direct memorization of the problem. For example, Ophir, Nass, and Wagner (2009) found that heavy media multitaskers had greater difficulty filtering out irrelevant stimuli from their environment in a filter task and a distracters task, were less likely to ignore irrelevant representations in memory in a two- and three-back task, and were less effective in suppressing the activation of irrelevant task sets when task-switching compared to lighter media multitaskers. An incentive in a dual-task situation may therefore only increase the likelihood that participants will direct attention to overall surface processing without being able to discriminate between relevant and irrelevant information. In order to test the impact of an incentive on memory in a multitasking situation we added irrelevant information to all word problems that our participants were asked to complete. Additionally, despite the null effects of incentives on problem type seen in previous research (Wieth \& Burns, 2006), we included both incremental and insight problems in this study due to previous research showing differences in the impact of a secondary task on problems involving creativity (e.g., Lavric, Forstmeier, \& Rippon 2000). However, given that we used similar problems to those used in Wieth and Burns we did not expect to see a difference in how the incentive would impact the incremental and insight problems.

In order to test our hypotheses participants were either given an incentive or not and asked to solve incremental and insight problems with irrelevant information added. Half of the participants simply solved the problems while the other half solved the problems while concurrently performing a tone monitoring task. After completing the problems participants were given a surprise memory test. 


\section{METHOD}

\section{PARTICIPANTS}

Three hundred and twenty Michigan State University students participated for course credit (mean age 19.62).

\section{MATERIALS}

\section{Incentive}

The incentive was the opportunity to leave the experiment early if participants solved four problems correctly. Wieth and Burns (2006) showed that this is an effective incentive that improves problem solving performance in college aged students.

\section{Problems}

Using a computer, participants were potentially given three incremental (age, water, and job problem) and three insight problems (month, matchstick, and prisoner problem). Participants were randomly assigned to receive the first four problems in one of four different orders such that participants received the two incremental problems (age and water) and the two insight problems (month and matchstick) in an alternating fashion. Each of the four problems was modified to include one piece of irrelevant information. For example, in the following problem: "Ann is twice as old as her son. They were both born in June. Ten years ago Ann was three times as old as her son. What are their present ages?" The information that Ann and her son were both born in June is not needed to solve the problem. A pilot study showed that participants consistently rated the added information as less relevant for solving the problem than relevant components of the problems. The last two problems (job and prisoner) were not modified to include irrelevant information because they were not used in any analyses due to the structure of the incentive. The text and solution rates of all problems can be found in the Appendix.

\section{Secondary Task}

Participants were asked to perform a concurrent tone monitoring task (based on Beilock, Bertenthal, McCoy, \& Carr; 2004). They were randomly assigned a $500 \mathrm{~ms}$ duration computer-generated target tone of $300 \mathrm{~Hz}$ or $1500 \mathrm{~Hz}$. They heard a tone every two seconds and were instructed to press a foot pedal when they heard the target tone.

\section{PROCEDURE}

Equal numbers of participants were randomly assigned to either the incentive or non-incentive and either single task or dual-task conditions. Participants were first given an informed consent document outlining the experiment and their rights as a participant. Following the consent procedure, participants were given an overview of the experiment including an example problem. Participants in the incentive condition were informed of the incentive and everyone was told that they would have four minutes to solve each problem. In neither the single or dual-task condition were participants told how many problems comprised this experiment. If participants asked they were simply told that the experiment would take them the whole experimental hour to complete.

All participants, regardless of condition, then completed a two-minute practice tone monitoring task. Each participant put on headphones and a target tone was played three times at an interval of one tone every two seconds. Participants were asked to press a foot pedal every time they heard the target tone. If a participant's hit rate was less than ninety percent they were asked to listen to the target tone again and repeat the practice task. After successfully completing the practice tone task, participants were given the tone monitoring task for four minutes to measure their baseline performance.

\section{Single-Task Condition}

Participants in the single task were then given an easy incremental practice problem (dinner party problem) and were reminded of the problem solving instructions. After completing the easy incremental problem they were given a chance to ask questions. They then completed up to six problems (three incremental and three insight).

\section{Dual-Task Condition}

Participants in the dual-task also completed the easy incremental problem and were told that they should perform the problem solving task and the tone task simultaneously, taking care to complete both. After completing the easy incremental problem (dinner party problem) concurrently with the tone task they were given a chance to ask questions. They then completed up to six problems (three incremental and three insight) while performing the tone monitoring task. Between problems they were given the option to listen to their target tone again.

After attempting four problems, all participants (regardless of condition) were presented with a surprise memory question that asked to write down as many details of each problem as they could remember. There was no time limit for this question and participants were not presented with tones. They then continued to solve problems, if necessary.

\section{RESULTS}

\section{PROBLEM SOLVING PERFORMANCE}

Only the first four problems were analyzed because participants in the incentive condition might not have attempted any other problems. An incremental problem solving score was calculated as the proportion correct of the two incremental problems, and an insight problem solving score as 
the proportion correct of the two insight problems. Note that although the data are categorical, an analysis of variance rather than a loglinear modeling analysis was used. Lunney's (1970) simulations show that ANOVA is a valid analysis for categorical data with large sample sizes and an equal number of participants in each condition. Using an ANOVA one can take advantage of the fact that participants did more than one problem, which is more problematic for loglinear analysis with its strong assumption of independence.

A $2 \times 2 \times 2$ ANOVA was performed on the incremental and insight scores with between-subjects factors of task (single or dual) and incentive (given or not), and a within-subjects factor of problem type (insight and incremental). There was a significant effect of task $\left(F[1,316]=17.36, p<.01, \eta_{p}^{2}=.052\right)$, indicating the dual-task condition decreased performance, and a significant effect for incentive, such that participants given an incentive outperformed those not given an incentive $\left(F[1,316]=5.25, p=.02, \eta_{p}^{2}=.016\right)$. These effects, however, were qualified by a significant interaction between incentive and task $\left(F[1,316]=3.92, p=.049, \eta_{p}^{2}=.012\right)$. Post-hoc tests showed that the incentive increased problem solving performance in the single-task condition $(t[158]=2.94, p=.004$, $d=.47)$ but not in the dual-task condition $(t[158]=.23, p=$ $.82, d=.04)$. See Figure 1 and Table 1 for means.

There was a significant main effect of type of problem $\left(F[1,316]=51.92, p<.01, \eta_{p}^{2}=.141\right)$, such that participants were more successful at solving incremental problems than insight problems. However, there were no significant interactions with problem type indicating that the dual-task and the incentive did not influence incremental and insight problems differently. No other interactions were significant. In addition the data investigating the impact of an incentive on problem solving success in the dual task condition and the single task condition was examined by estimating a Bayes factor for each of the two comparisons. Using Bayesian Information Criteria (Wagenmaker, 2007) the fit of the data under the null hypothesis and the alternative hypothesis are compared. Looking at the impact of the incentive in the

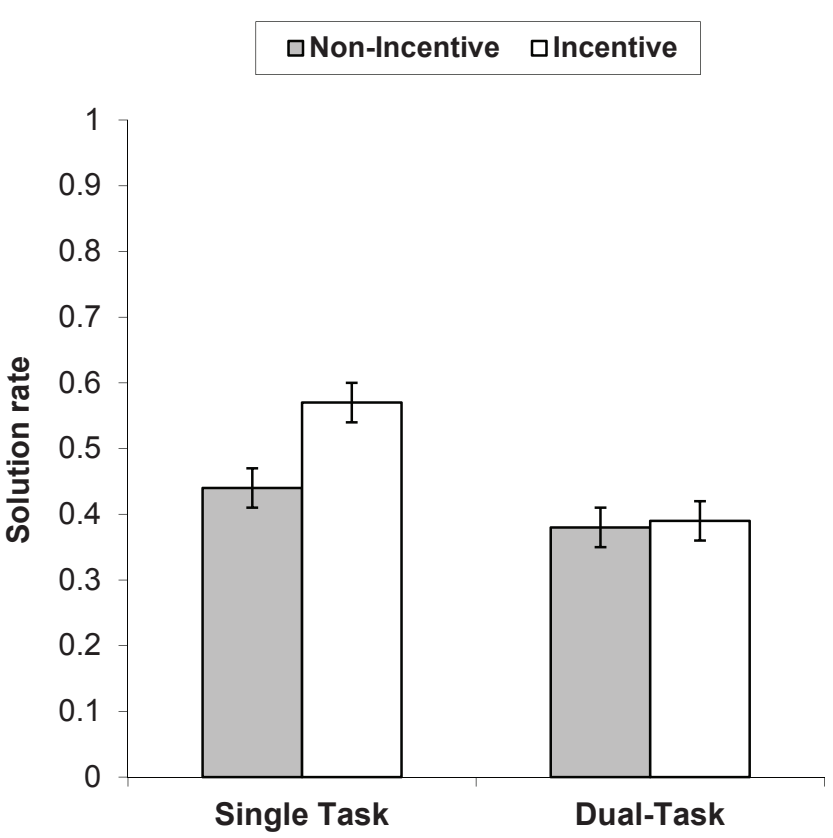

Figure 1.

Mean problem solution rate for participants in the single and dual-task conditions across incentive. Error bars represent the standard error of the mean.

single task condition an estimated Bayes factor (null/alternative) suggests that the data are .15:1 in favor of the alternative hypothesis, or rather, 6.67 times more likely to occur under a model including an effect of incentive, rather than a model without it. On the other hand, looking at the impact of the incentive in the dual-task condition an estimated Bayes factor (null/alternative) suggests that the data are 12.28:1 in favor of the alternative hypothesis, or rather, .08 times more likely to occur under the model including an effect of incentive, rather than a model without it. Overall these results show that the incentive led to an increase in problem solving performance only in the single task condition while showing little to no impact of an incentive while solving problems when multitasking (showing the usual detrimental effects of multitasking on problem solving).

\section{Table 1.}

Mean incremental and insight problem solving scores (standard deviations in parentheses) for participants in the single and dual-task conditions divided by incentive.

\begin{tabular}{|c|c|c|c|}
\hline & Incremental & Insight & Overall \\
\hline \multicolumn{4}{|l|}{ Single Task } \\
\hline Non-incentive $(\mathrm{n}=80)$ & $.53(.34)$ & $.36(.33)$ & $.44(.24)$ \\
\hline Incentive $(\mathrm{n}=80)$ & $.66(.36)$ & $.48(.39)$ & $.57(.31)$ \\
\hline Total $(\mathrm{n}=160)$ & $.60(.36)$ & $.42(.37)$ & $.51(.28)$ \\
\hline \multicolumn{4}{|l|}{ Dual Task } \\
\hline Non-incentive $(\mathrm{n}=80)$ & $.47(.36)$ & $.29(.32)$ & $.38(.25)$ \\
\hline Incentive $(\mathrm{n}=80)$ & $.48(.36)$ & $.29(.33)$ & $.39(.27)$ \\
\hline Total $(\mathrm{n}=160)$ & $.48(.36)$ & $.29(.32)$ & $.38(.26)$ \\
\hline
\end{tabular}




\section{SECONDARY TASK PERFORMANCE}

Performance on the secondary task was evaluated to determine how dual-task participants were allocating their attentional resources. Tone detection accuracy for when participants were performing the tone task only, performing the tone task while solving incremental problems, and while solving insight problems was calculated by subtracting participants' proportion of tones incorrectly judged to be the target tone from their proportion of target tones correctly identified.

A $2 \times 3$ ANOVA was run on the accuracy measure with a between subject factor of incentive (given or not) and a within subjects factor of tone type (tone only baseline, tone incremental, and tone insight). See Table 2 for means. There was a main effect of tone type $(F[2,316]=129.49, p<.01$, $\left.\eta_{p}^{2}=.453\right)$, such that participants were more accurate when performing the tone task alone than when solving incremental problems, $t(159)=14.47, p<.01, d=.2 .30$, and insight problems, $t(159)=11.35, p<.01, d=1.80$. Tone task accuracy did not differ between incremental and insight problem solving $(t[159]=.81, p=.21, d=.13)$. There was no incentive effect $\left(F[1,158]=.41, p=.52, \eta_{p}^{2}=.003\right)$ nor an interaction between it and tone type $\left(F[2,316]=.38, p=.69, \eta_{p}^{2}=.003\right)$. See Figure 2 for means. Thus the incentive did not influence tone monitoring accuracy.

Looking at the impact of the incentive on tone monitoring by estimating a Bayes factor (null/alternative), it was found that the data are 219.89:1 in favor of the alternative hypothesis, or rather, .005 times more likely to occur under the model including an effect of incentive, rather than the model without it. A similar overall pattern of results was found for tone monitoring response time. See Figure 3.

These findings indicate that participants' ability to perform the tone task is influenced by concurrent problem solving but not the incentive. Perhaps incentives cause an increase in attention to the rewarded task only when additional or spare resources are available to the solver. When participants do not have any additional attentional resources

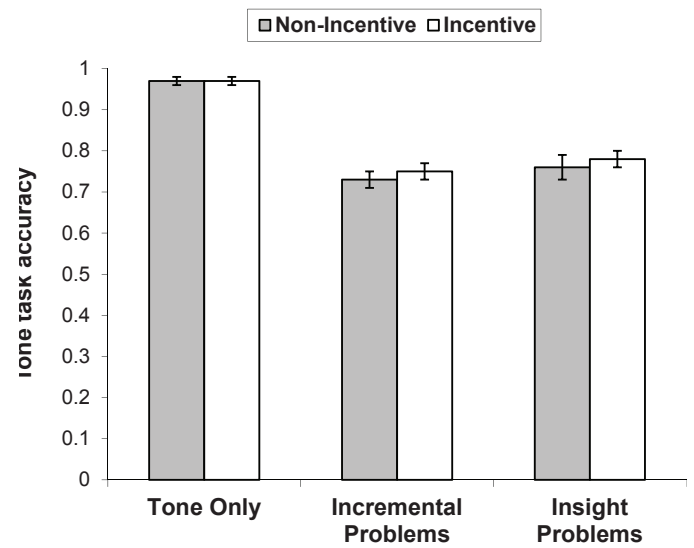

Figure 2.

Tone task performance means for accuracy by tone type: tone only (baseline collected before start of problem solving), insight problems (collected during insight problem solving) and incremental problems (collected during incremental problem solving). Error bars represent the standard error of the mean.

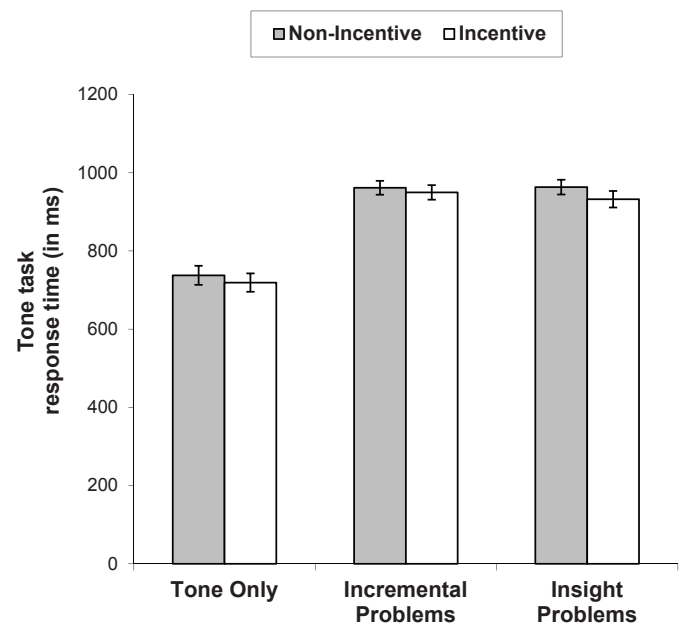

Figure 3.

Tone task performance means for response times (in msec) by tone type: tone only (baseline collected before start of problem solving), insight problems (collected during insight problem solving) and incremental problems (collected during incremental problem solving). Error bars represent the standard error of the mean.

Table 2.

Tone task performance means for accuracy and response times (in msec), by tone type: tone only (baseline collected before start of problem solving), insight (collected during insight problem solving) and incremental (collected during incremental problem solving).

\begin{tabular}{|l|c|c|c|}
\hline & Incremental & Insight & Tone Only \\
\hline Accuracy & $.73(.20)$ & $.76(.26)$ & $.97(.11)$ \\
\hline Non-incentive $(\mathrm{n}=80)$ & $.75(.22)$ & $.78(.20)$ & $.97(.13)$ \\
\hline Incentive $(\mathrm{n}=80)$ & $.74(.21)$ & $.77(.23)$ & $.97(.12)$ \\
\hline Total $(\mathrm{n}=160)$ & & \\
\hline Response Time & $962(159)$ & $963(168)$ & $734(231)$ \\
\hline Non-incentive $(\mathrm{n}=80)$ & $950(165)$ & $932(189)$ & $715(214)$ \\
\hline Incentive $(\mathrm{n}=80)$ & $956(162)$ & $948(179)$ & $725(222)$ \\
\hline Total $(\mathrm{n}=160)$ &
\end{tabular}




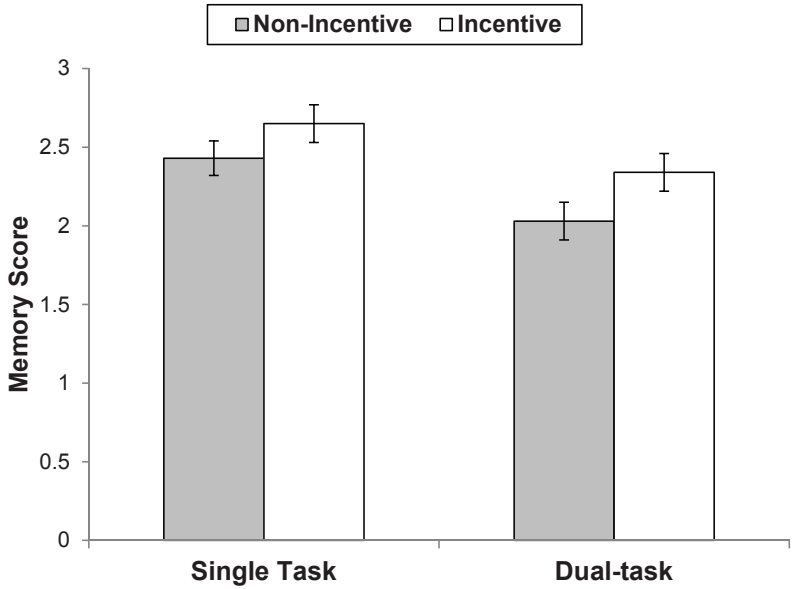

Figure 4.

Mean problem memory score for participants in the single and dual-task conditions across incentive. Error bars represent the standard error of the mean.

that can be shifted (as in the dual-task condition) incentives may not have an impact on problem solving performance.

\section{MEMORY}

In order to determine the impact of an incentive on problem solving in a dual-task situation, a problem memory measure was created by scoring participants' responses to the memory question for the amount of detail given for each problem. Two raters, blind to condition, independently scored each of the problem responses on a rating scale ranging from 1 to $4(1=$ very little or no detail about a problem, $4=$ all or almost all the details of a problem). If participants did not mention a problem a score of 0 was assigned for that particular problem. Inter-rater reliability was found to be satisfactory $(K=.89)$.

A $2 \times 2 \times 2$ ANOVA was performed on the problem memory measure with between subjects factors of task (single or dual), incentive (given or not), and a within subjects factor of problem type (incremental and insight). See Table 3 for means. There was an effect for task, $F(1,316)=5.87, p=.02, \eta_{p}{ }^{2}=$ .016 showing the expected decrease in memory for problem

Table 3.

Mean problem memory scores for incremental and insight problems (standard deviations in parentheses) in the single and dualtask incentive and non-incentive conditions.

\begin{tabular}{|c|c|c|c|}
\hline & Incremental & Insight & Overall \\
\hline \multicolumn{4}{|l|}{ Single Task } \\
\hline Non-incentive $(\mathrm{n}=80)$ & $2.35(1.19)$ & $2.50(1.19)$ & $2.43(1.01)$ \\
\hline Incentive $(\mathrm{n}=80)$ & $2.58(1.33)$ & $2.73(1.12)$ & $2.65(1.07)$ \\
\hline Total $(n=160)$ & $2.46(1.26)$ & $2.62(1.16)$ & $2.54(1.04)$ \\
\hline \multicolumn{4}{|l|}{ Dual Task } \\
\hline Non-incentive $(\mathrm{n}=80)$ & $1.97(1.31)$ & $2.08(1.28)$ & $2.03(1.10)$ \\
\hline Incentive $(\mathrm{n}=80)$ & $2.47(1.28)$ & $2.48(1.23)$ & $2.48(1.25)$ \\
\hline Total $(\mathrm{n}=160)$ & $2.21(1.32)$ & $2.28(1.27)$ & $2.25(1.12)$ \\
\hline
\end{tabular}

details in the dual task compared to the single task condition. There was also an effect of incentive $(F[1,316]=7.92, p=$ $.005, \eta_{p}^{2}=.024$ ), such that participants in the incentive condition remembered more problem details than participants in the non-incentive condition. See Figure 4 for means.

There was no effect of problem type $(p=.115)$, or any significant interactions. Examining the impact of an incentive on problem memory by estimating a Bayes factor shows that the data were .25:1 in favor of the alternative hypothesis, or rather, 4 times more likely to occur under the model including an effect of incentive, rather than the model without it. The finding that participants in the dual-task condition given an incentive remember more problem details than those not given an incentive indicates that the incentive is somehow changing how participants are processing the information.

\section{Irrelevant information}

Participants' memory data was scored for recall of the piece of irrelevant information in each problem. If a participant's problem recall contained the irrelevant information it was scored as a 1 , if it did not it was scored as a 0 . An irrelevant incremental-score and irrelevant insight-score were then calculated by averaging across the appropriate problems.

A $2 \times 2 \times 2$ ANOVA was run on the irrelevant scores with between subjects factors of task (single or dual) and incentive (given or not) and a within subjects factor of problem type (incremental and insight). For means see Table 4 . There was no effect of task $\left(F[1,316]=.24, p=.63, \eta_{p}^{2}=.001\right)$ nor an effect of incentive $\left(F[1,316]=.36, p=.55, \eta_{p}{ }^{2}=.001\right)$. There was an effect for problem type $(F[1,316]=20.34, p<$ $\left..01, \eta_{p}^{2}=.060\right)$ such that participants remembered more irrelevant information for insight than incremental problems. Insight problems tend to be shorter which might have led participants to remember them more. It is important to note however, that problem type did not significantly interact with incentive $(p=.69)$ nor task $(p=.18)$.

There was a significant interaction between task and incentive $\left(F[1,316]=6.52, p=.01, \eta_{p}{ }^{2}=.020\right)$. Post-hoc tests 


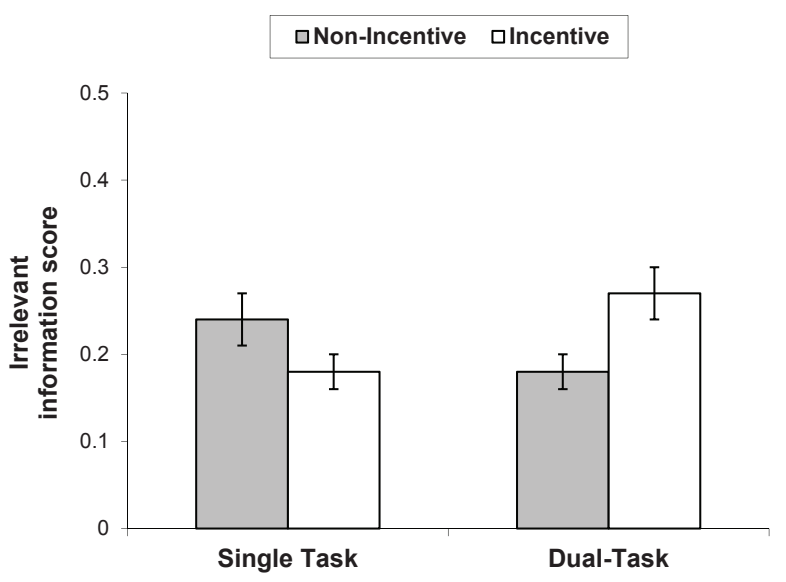

Figure 5.

Mean irrelevant information score for the single and dual-task conditions for participants either given an incentive or not.

Error bars represent the standard error of the mean.

revealed that in the dual-task condition participants given an incentive recalled more pieces of irrelevant information than participants not given an incentive $(t[158]=2.26, p=.03, d=$ .36), however there was no significant effect in the single task condition $(t[158]=1.43, p=.16, d=.23)$ although the trend was in the opposite direction. See Figure 5.

All other interactions were not significant. In addition, the data investigating the impact of an incentive on the recall of irrelevant information in the dual-task condition and the effect of an incentive in the single task condition were examined by estimating Bayes factors for each analysis. For the effect of an incentive on memory for irrelevant information in the dual-task condition the estimated Bayes factor (null/ alternative) is .50:1 in favor of the alternative hypothesis, or rather, 2 times more likely to occur under the model including an effect of an incentive, rather than a model without it. Alternatively, for the effect of an incentive on memory for irrelevant information in the single task condition the estimated Byes factor (null/alternative) is $4.50: 1$, or rather .22 times more likely to occur under the model including an effect of an incentive, rather than a model without it.

\section{Table 4.}

Mean irrelevant information scores for incremental and insight problems (standard deviations in parentheses) in the single and dual-task incentive and non-incentive conditions.

\begin{tabular}{|l|c|c|c|}
\hline & Incremental & Insight & Overall \\
\hline Single Task & $.20(.33)$ & $.28(.32)$ & $.24(.26)$ \\
\hline Non-incentive $(\mathrm{n}=80)$ & $.16(.29)$ & $.21(.28)$ & $.18(.24)$ \\
\hline Incentive $(\mathrm{n}=80)$ & $.18(.31)$ & $.24(.30)$ & $.21(.25)$ \\
\hline Total $(\mathrm{n}=160)$ & $.13(.26)$ & $.23(.32)$ & $.18(.24)$ \\
\hline Dual Task & $.21(.34)$ & $.33(.35)$ & $.27(.29)$ \\
\hline Non-incentive $(\mathrm{n}=80)$ & $.17(.30)$ & $.28(.33)$ & $.23(.27)$ \\
\hline Incentive $(\mathrm{n}=80)$ & &
\end{tabular}

The aims of this study were to examine whether an incentive can have an impact on problem solving while in a multitasking situation. Our study's results showed an improvement due to an incentive only in the single-task condition. In addition, performance decrements were also seen in the secondary task (tone task) regardless of incentive condition. These findings indicate that an incentive is not able to override the attentional limits present in the system and therefore cannot ameliorate the negative effects of multitasking while problem solving. Participants, though seemingly interested in meeting the requirements of the incentive (as seen in the memory data), were not able to allocate an appropriate amount of attentional resources to the problem solving task. These findings are inconsistent with Charron and Koechlin (2010) who found that participants switched their attentional resources based on the value of the incentive. Perhaps this is due to the differences in complexities of the tasks that were being performed. In Charron and Koechlin participants were asked to switch between similar letter sequencing tasks which asked participants to judge whether two successively presented letters are also in immediate succession in the word "tablet" on each trial. In contrast, in the current study participants were presented with complex word problems that not only require memory but also the ability to find a correct representation of the task, the ability to implement potential solution steps, and the ability to focus and sustain ones attention on the task. It is therefore possible that an incentive when multitasking is only effective in directing attention when the brain is engaging in less cognitively complex tasks. Future research needs to be done to investigate the role that task complexity plays in the relationship between incentives and multitasking.

Furthermore, this study was designed to investigate the impact of a dual-task situation and an incentive on memory for problems. Results showed that overall the incentive increased participants' memory for problem details. The incentive increased problem recall for both the single and the 
dual-task condition despite overall recall being lower in the dual-task than in the single-task condition. These findings indicate that participants given an incentive in the dual-task condition are able to allocate some resources to the problem solving task which led to an increase in memory. This is quite surprising in light of the problem solving accuracy results indicating an increase in problem solving only for the single task condition. In order to fully understand these findings though, the memory results for the irrelevant information in each problem need to be considered. It was found that participants given an incentive in the dual-task condition recalled more irrelevant pieces of information than participants not given an incentive. These findings indicate that an incentive in a multitasking situation may lead to more surface processing of a problem instead of deeper processing needed to solve complex word problems. These findings are consistent with Foerde, Knowlton, and Poldrack (2006) that showed that a dual-task condition disrupted activity in the medial temporal lobe, which is associated with more declarative learning, but did not change the activity in the striatal area, which is associated with habit learning. In addition, Foerde, Knowlton, and Poldrack argued that habitual learning associated with activation in the striatal area is much less flexible in its use, such that it is not as easily applied in different situations. It is therefore possible that participants given the incentive in the dual-task condition switched to more habitual or surface type processing (perhaps reading the problem over and over again) which led to the increase in overall memory. This type of processing, however, cannot be used to differentiate between relevant and irrelevant pieces of information, which in turn led to lower problem solving success compared to participants in the single-task condition. Similar results can be seen in Ricks and Wiley (2014) were suspected surface processing did not impact memory for a baseball cover story but reduced learning of statistics concepts within the cover story.

Our results are also consistent with Ophir, Nass, and Wagner (2009) that found evidence for greater irrelevant information processing among media multitaskers. As discussed above, heavy multitaskers showed greater susceptibility to distraction from irrelevant information in the environment and from irrelevant representation in memory. It is possible then that the more often one engages in multitasking the more readily the brain uses surface or habitual type processing, which ultimately leads to decrements in performance.

The current studies' findings of greater surface processing may also speak to the increasing number of studies investigating multitasking that have shown a disconnect between an individual's actual multitasking ability and their metacognitive judgment about their ability. Several studies using closed-circuit driving tasks found that participants recognized that their driving suffered when performing a secondary task (such as mental arithmetic, digit recognition, or a guessing game) but that their estimates of decrement did not correspond well to their actual decrements (Horrey, Lesch, \& Garabet, 2008, 2009; Lesch \& Hancock, 2004). Similarly, Sanbonmatsu, Strayer, Medeiros-Ward, and Watson (2013) found that participants tend to overestimate their general ability to multitask, relative to others. Investigating preperformance predictions, Finley, Benjamin, and McCarley (2014) found no relationship between participants predicted and actual performance decrements on a visual task while performing and auditory secondary task. Based on the results of the current study, it is possible that motivation may play a role in participants' faulty metacognitive judgments. As seen in the dual-task condition, an incentive (motivation) led to an increase in surface processing of the problems which in turn led to greater overall memory. It is possible that when individuals are motivated this increase in surface processing is misinterpreted when making metacognitive judgments about performance. Perhaps participants that are more motivated see their efforts to be more effective than they actually are, leading to a disconnect between actual ability and estimates of ability. Future studies should be designed to test this possibility.

\section{INSIGHT VERSUS INCREMENTAL PROBLEMS}

Throughout this experiment both incremental and insight problems were used to investigate possible differences in how the concurrent tone monitoring task might affect these types of problems. Lavric et al. (2000) found negative effects of a secondary task on what they labeled as an incremental problem (Wason card selection task) but not on what they labeled as an insight problem solving (Duncker's candle problem). Our results do not replicate these findings; instead the secondary task reduced both incremental and insight problem solving. It is possible that our findings did not replicate the results of Lavric et al. because of the difference in the insight problem solving tasks that were used across the two studies. Insight problem solving has been proposed to occur in three stages: search for an initial problem representation, reaching an impasse, and restructuring the problem representation. Ash and Wiley (2006) found that participants' ability to control attention (as measured through working memory capacity) predicted successful insight problem solving that required both a successful search phase and restructuring phase for problem solving success. Ability to control attention, however, did not predict success on those problems that only required successful restructuring. Given that problem solving success for Duncker's candle problem mostly hinges on the successful restructuring of the function of the box of tacks, while the insight problems used in the current study require participants to both search for an initial representation as well as successfully restructure the problem space, it is possible that a secondary task designed to tax attentional 
resources will have a different impact on these different types of insight problems. Indeed DeCaro, Van Stockum, and Wieth (under review) found that participants' level of working memory (and therefore the ability to control attention) influences insight problems that emphasize these stages of problem solving differently. In addition, it is also possible that, by including irrelevant information in each problem, we altered the problem solving processes associated with these problems. Therefore, comparisons between the data in this study and other studies using incremental and insight problems may be more difficult. Further research needs to investigate this possibility.

It is also possible that our results differ from Lavric et al. because of the differences in the secondary tasks. Murray and Byrne (2005) found a relationship between insight problem solving success and participants ability to switch their attention but not measures of sustained attention and selective attention. Lavric et al. used a secondary tone task where participants were asked to count the number of target tones while our participants were asked to respond by pressing a foot pedal in response to a target tone. Perhaps the secondary task used by Lavric et al. required more sustained and selective attentional processing while the secondary task in the current study relied more heavily on switches in attention (i.e., participants were switching between pressing the foot pedal for the tone monitoring task and problem solving more so than between the tone counting task and problem solving). Future studies should be conducted to disentangle the relationship between different type of insight problems and the different secondary tasks used.

\section{CONCLUSIONS}

Overall, the current study shows that an incentive was not able to increase problem solving success in a multitasking situation. Instead providing an incentive seemed to encourage more superficial or habitual processing, resulting in greater memory for irrelevant problem components. This indicates that educators and employers should think twice before using incentives to discourage students and workers from multitasking. It is possible that incentives may even further add to decreases in performance by leading to faulty performance judgments. Perhaps by encouraging more targeted metacognitive processing (see Belenky \& Nokes, 2009 for an example) distracted multitaskers can be encouraged to devote more of their attentional resources to one task at a time.

\section{ACKNOWLEDGEMENTS}

The authors would like to thank Andrea Francis, Sian Beilock, Rose Zacks, Tom Carr, Zach Hambrick, Jonathan Nycz, and Tom Getty for their helpful comments regarding this research.

\section{REFERENCES}

Armstrong, G. B., Boiarsky, G. A., \& Mares, M. L. (1991). Background television and reading performance. Communication Monographs, 58(3), 235-253. http://dx.doi.org /10.1080/03637759109376228

Ash, I. K., \& Wiley, J. (2006). The nature of re-structuring in insight: An individual-differences approach. Psychonomic Bulletin and Review, 13(1), 66-73. http://dx.doi.org /10.3758/BF03193814

Beilock, S. L., Bertenthal, B. I., McCoy, A. M., \& Carr, T. H. (2004). Haste does not always make waste: Expertise, direction of attention, and speed versus accuracy performing sensorimotor skills. Psychonomic Bulletin \& Review, 11(2), 373-379. http://dx.doi.org/10.3758/BF03196585

Belenky, D. M., \& Nokes, T. J. (2009) Examining the role of manipulatives and metacognition on engagement, learning, and transfer. The Journal of Problem Solving, 2(2), 102-129. http://dx.doi.org/10.7771/1932-6246.1061

Bowman, L. L., Levine, L. E., Waite, B. M., \& Dendron, M. (2010). Can students really multitask? An experimental study of instant messaging while reading. Computers \& Education, 54(4), 927-931. http://dx.doi.org/10.1016 /j.compedu.2009.09.024

Casserly, M. (2012, Dec. 10). The 10 skills that will get you hired in 2013. Forbes.com. Retrieved from http://www. forbes.com/sites/meghancasserly/2012/12/10/the-10 -skills-that-will-get-you-a-job-in-2013/

Charron, S., \& Koechlin, E. (2010). Divided representation of concurrent goals in the human frontal lobes. Science, 328(5976), 360-363. http://dx.doi.org/10.1126/science.1183614

Common CoreStateStandards Initiative. (2014). Preparing America's students for success. Corestandards.org. Retrieved from http://www.corestandards.org/what-parents-should-know/

Deci, E. L., Koestner, R., \& Ryan, R. M. (1999). A meta-analytic review of experiments examining the effects of extrinsic rewards on intrinsic motivation. Psychological Bulletin, 125(6), 627-668.

DeCaro, M. S., Van Stockum, C. A., \& Wieth, M. B. (under review). When higher working memory capacity hinders insight. Manuscript submitted for publication.

Finley, J. R., Benjamin, A. S., \& McCarley, J. S. (2014). Metacognition of multitasking: How well do we predict the costs of divided attention? Journal of Experimental Psychology: Applied, 20(2), 158-165. http://dx.doi.org/10.1037/xap0000010

Foerde, L., Knowlton, B. J., \& Poldrack, R. A. (2006). Distraction modulates the engagement of competing memory systems. Proceedings of the National Academy of Sciences, 103(31), 11778-11783.

FuzeBox. (2014). FuzeBox survey reveals U.S. workforce hampered by multitasking and disengagement [Press release]. PRNewswire. Retrieved from http://www.prnewswire.com 
/news-releases/fuzebox-survey-reveals-us-workforce -hampered-by-multitasking-and-disengagement -242214401.html

Gilhooly, K. J., Logie, R. H., Wetherick, N. E., \& Wynn, V. (1993). Working memory and strategies in syllogistic reasoning tasks. Memory \& Cognition, 21(1), 115-124. http:// dx.doi.org/10.3758/BF03211170

Glucksberg, S. (1962). The influence of strength of drive on functional fixedness and perceptual recognition. Journal of Experimental Psychology, 63(1), 36-41. http://dx.doi.org /10.1037/h0044683

Goddard, L., Dritschel, B., \& Burton, A. (1998). Gender differences in the dual-task effects on autobiographical memory retrieval during social problem solving. British Journal of Psychology, 89(4), 611-627. http://dx.doi.org /10.1111/j.2044-8295.1998.tb02706.x

Hambrick, D. Z., \& Engle, R. W. (2003). The role of working memory in problem solving. In J. E. Davidson, \& R. J. Sternberg (Eds.), The Psychology of Problem Solving (pp. 176-206). New York, NY: Cambridge University Press.

Horrey, W. J., Lesch, M. F., \& Garabet, A. (2008). Assessing the awareness of performance decrements in distracted drivers. Accident Analysis and Prevention, 40(2), 675-682. http://dx.doi.org/10.1016/j.aap.2007.09.004

Horrey, W. J., Lesch, M. F., \& Garabet, A. (2009). Dissociation between driving performance and drivers' subjective estimates of performance and workload in dual-task situations. Journal of Safety Research, 40(1), 7-12. http:// dx.doi.org/10.1016/j.jsr.2008.10.011

Jarosz, A. F., Colflesh, G. J. H., \& Wiley, J. (2012). Uncorking the muse: Alcohol intoxication facilitates creative problem solving. Consciousness and Cognition Journal, 21(1), 487-493. http://dx.doi.org/10.1016/j.concog.2012.01.002

Jenkins, G. D., Mitra, A., Gupta, N., \& Shaw, J. D. (1998). Are financial incentives related to performance? A meta-analytic review of empirical research. Journal of Applied Psychology, 83(5), 777-787. http://dx.doi.org /10.1037/0021-9010.83.5.777

Kahneman, D. (1973). Attention and effort. Englewood Cliffs, NJ: Prentice Hall.

LaMere, J. M., Dickinson, A. M., Henry, G., Henry, M., \& Poling, A. D. (1996). Effects of a multicomponent monetary incentive program on the performance of truck drivers. Behavior Modification, 20, 385-405. http://dx.doi.org /10.1177/01454455960204002

Lavric, A., Forstmeier, S., \& Rippon, G. (2000). Differences in working memory involvement in analytical and creative tasks: An ERP study. Neuroreport: For Rapid Communication of Neuroscience Research, 11(8), 1613-1618. http:// dx.doi.org/10.1097/00001756-200006050-00004

Lesch, M. F., \& Hancock, P. A. (2004). Driving performance during concurrent cell-phone use: Are drivers aware of their performance decrements? Accident Analysis and Prevention, 36(3), 471-480. http://dx.doi.org/10.1016 /S0001-4575(03)00042-3

Lin, W.-L., \& Lien, Y.-W. (2013). The different role of working memory in open-ended versus close-ended creative problem solving: A dual-process theory account. Creativity Research Journal, 25(1), 85-96. http://dx.doi.org/10.1080 /10400419.2013.752249

Logan, G. D., Taylor, S. E., \& Etherton, J. L. (1996). Attention in the acquisition and expression of automaticity. Journal of Experimental Psychology: Learning, Memory, and Cognition, 22, 620-638.

Logie, R. H., Gilhooly, K. J., \& Wynn, V. (1994). Counting on working memory in arithmetic problem solving. Memory \& Cognition, 22(4), 395-410. http://dx.doi.org/10.3758 /BF03200866

Luchins, A. (1942). Mechanization in problem solving: The effect of Einstellung. Psychological Monographs, 54(6), Whole No. 248.

Lunney, G. H. (1970). Using analysis of variance with a dichotomous dependent variable: An empirical study. Journal of Educational Measurement, 7(4), 263-269. http:// dx.doi.org/10.1111/j.1745-3984.1970.tb00727.x

McGraw, K., \& McCullers, J. (1979). Evidence of a detrimental effect of extrinsic incentives on breaking a mental set. Journal of Experimental Social Psychology, 15(3), 285-294. http://dx.doi.org/10.1016/0022-1031(79)90039-8

Meuter, R. F. I., \& Allport, A. (1999). Bilingual language switching in naming: Asymmetrical costs of language selection. Journal of Memory and Language, 40(1), 25-40. http://dx.doi.org/10.1006/jmla.1998.2602

Murray, M. A., \& Byrne, R. M. J. (2005). Attention and working memory in insight problem solving. Proceedings of Cognitive Science Society, 27, 1571-1575.

Ophir, E., Nass, C., \& Wagner, A. D. (2009). Cognitive control in media multitaskers. Proceedings of the National Academy of Sciences, 106(37), 15583-15587. http://dx.doi.org /10.1073/pnas.0903620106

Pool, M. M., Koolstra, C. M., \& van der Voort, T. H. A. (2003): The impact of background radio and television on high school students' homework performance. Journal of Communication, 53(1), 74-87. http://dx.doi. org/10.1111/j.1460-2466.2003.tb03006.x

Ricks, T. R., \& Wiley, J. (2014). Effects of cover stories on problem solving in a statistics course. The Journal of Problem Solving, 7(1), Article 6. Retrieved from http://docs.lib .purdue.edu/jps/vol7/iss $1 / 6$

Rideout, V. J., Foehr, U. G., \& Roberts, D. F (2010). Generation M: Media in the lives of 8-18 year olds. Menlo Park, CA: Kaiser Family Foundation. Retrieved from http:// kaiserfamilyfoundation.files.wordpress.com/2010/01 /mh012010presentl.pdf 
Rubinstein, J. S., Meyer, D. E., \& Evans, J. Riedel, J. A., Nebecker, D. M., \& Cooper, B. L. (1988). The influence of monetary incentives on goal choice, goal commitment, and task performance. Organizational Behavior and $\mathrm{Hu}$ man Decision Processes, 42(2), 155-180. http://dx.doi.org /10.1016/0749-5978(88)90010-6

Rogers, R. D. \& Monsell, S. (1995). Costs of a predictable switch between simple cognitive tasks. Journal of Experimental Psychology: General, 124(2), 207-231.

Rosen, L. D., Carrier, L. M., \& Cheever, N. A. (2013). Facebook and texting made me do it: Media-induced task-switching while studying. Computers in Human Behavior, 29(3), 948-958. http://dx.doi.org/10.1016/j.chb.2012.12.001

Rubinstein, J. S., Meyer, D. E., \& Evans, J. E. (2001). Executive control of cognitive processes in task switching. Journal of Experimental Psychology: Human Perception and Performance, 27(4), 763-797. http://dx.doi.org /10.1037/0096-1523.27.4.763

Saari, L. M., \& Latham, G. P. (1982). Employee reaction to continuous and variable ratio reinforcement schedules involving a monetary incentive. Journal of Applied Psychology, 67(4), 506-508. http://dx.doi.org/10.1037/0021-9010.67.4.506

Sanbonmatsu, D. M., Strayer, D. L., Medeiros-Ward, N., \& Watson, J. M. (2013). Who multi-tasks and why? Multitasking ability, perceived multi-tasking ability, impulsivity, and sensation seeking. PLOS ONE, 8(1), e54402. http:// dx.doi.org/10.1371/journal.pone.0054402

Taatgen, N. A. (2011). The minimal control principle predicts strategy shifts in the abstract decision making task. The Journal of Problem Solving, 3(2), 151-166. Retrieved from http://dx.doi.org/10.7771/1932-6246.1095

Van Stockum, C. A., Jr., \& DeCaro, M. S. (2014). Enclothed cognition and controlled attention during insight problemsolving. The Journal of Problem Solving, 7(1), Article 8. Retrieved from http://docs.lib.purdue.edu/jps/vol7/iss $1 / 8$

Wagenmakers, E. J. (2007). A practical solution to the pervasive problems of $p$ values. Psychonomic Bulletin and Review, 14(5), 779-804.

Wickens, C. D. (1980). The structure of attentional resources. In R. S. Nickerson (Ed.), Attention and performance VIII (pp. 239-257). Hillsdale, NJ: Erlbaum.

Wickens, C. D. (1984). Processing resources in attention. In R. Parasuraman \& R. Davies (Eds.), Varieties of attention (pp. 63-101). Orlando, FL: Academic Press.

Wieth, M., \& Burns, B. D. (2006). Incentives improve performance on both incremental and insight problem solving. Quarterly Journal of Experimental Psychology, 59(8), 13781394. http://dx.doi.org/10.1080/17470210500234026

Wieth, M. B., \& Zacks, R. T. (2011). Time of day effects on problem solving: When the non-optimal is optimal. Thinking \& Reasoning, 17(4), 387-401. http://dx.doi.org/ $10.1080 / 13546783.2011 .625663$
Yeung, N., \& Monsell, S. (2003). Switching between tasks of unequal familiarity: The role of stimulus-attribute and response-set selection. Journal of Experimental Psychology: Human Perception and Performance, 29(2), 455-469. http://dx.doi.org/10.1037/0096-1523.29.2.455 


\section{APPENDIX}

Text and solution rates of the incremental and insight problems. The added irrelevant information is shown in bold.

\section{INCREMENTAL PROBLEMS}

Practice problem: Dinner Party Problem (solution rate: 89\%, not included in any analyses)

Mary won't eat fish or spinach, Sally won't eat fish or green beans, Steve won't eat shrimp or potatoes, Alice won't eat beef or tomatoes. If you are willing to give such a bunch of fussy eaters a dinner party, which items from the following list can you serve: green beans, creamed codfish, roast beef, roast chicken, celery, and lettuce.

\section{Age Problem (solution rate: 65\%)}

Ann is twice as old as her son. They were both born in June. Ten years ago Ann was three times as old as her son. What are their present ages?

\section{Water Problem (solution rate: $36 \%$ )}

Given containers of $163,14,25$, and 11 ounces, and a source of unlimited water, obtain exactly 77 ounces of water (1 milliliter $=.034$ ounces).

\section{Job Problem (solution rate: $51 \%$, not included in any analyses)}

Lebrun, Lenoir, and Leblanc are, not necessarily in that order, the accountant, warehouseman, and traveling salesman of a firm. The salesman, a bachelor, is the youngest of the three. Lebrun, who is Lenoir's son in law, is taller than the warehouseman. Who has what job?

\section{INSIGHT PROBLEMS}

Month Problem (solution rate: $46 \%$ )

What occurs once in June and twice in August, but never occurs in October regardless if you are looking at a Gregorian or Julian calendar?

\section{Matchstick Problem (solution rate: 26\%)}

Correct the arithmetic statement expressed in Roman numerals by moving a single matchstick from one position in the statement to another. Remember putting a smaller number in front of a larger number means subtraction.

$$
\mathrm{XI}=\mathrm{III}+\mathrm{III}
$$

\section{Prisoner Problem (solution rate: 61\%, not included in any analyses)}

A prisoner was attempting to escape from a tower. He found in his cell a rope that was half long enough to permit him to reach the ground safely. He divided the rope in half, tied the two parts together, and escaped. How could he have done this? 